\title{
Activity-Guided Fractionation of Green Tea Extract with Antiproliferative Activity against Human Stomach Cancer Cells ${ }^{1)}$
}

\author{
Junei Kinjo, ${ }^{*}, a$ Tsuneatsu NagaO, ${ }^{a}$ Takashi Tanaka, ${ }^{b}$ Gen-ichiro Nonaka, ${ }^{c}$ Masafumi OKawa, ${ }^{d}$ \\ Toshihiro NOHARA, ${ }^{d}$ and Hikaru OKABE ${ }^{a}$ \\ ${ }^{a}$ Faculty of Pharmaceutical Sciences, Fukuoka University; 8-19-1 Nanakuma, Jonan-ku, Fukuoka 814-0180, Japan: \\ ${ }^{b}$ School of Pharmaceutical Sciences, Nagasaki University; 1-14 Bunkyomachi, Nagasaki 852-8521, Japan: ${ }^{c}$ Usaien \\ Pharm. Co., Ltd.; 1-3-17 Zaimoku, Saga 840-0055, Japan: and 'Faculty of Pharmaceutical Sciences, Kumamoto \\ University; 5-1 Oe-honmachi, Kumamoto 862-0973, Japan. Received March 4, 2002; accepted May 16, 2002
}

\begin{abstract}
Epidemiological studies have suggested that the consumption of green tea provides protection against stomach cancer. Fractionation of green tea extract, guided by antiproliferative activity against human stomach cancer (MK-1) cells, has resulted in the isolation of six active flavan-3-ols, epicatechin (EC), epigallocatechin (EGC), epigallocatechin gallate (EGCg), gallocatechin (GC), epicatechin gallate (ECg), gallocatechin gallate (GCg), together with inactive glycosides of kaempferol and quercetin. Among the six active flavan-3-ols, EGCg and GCg showed the highest activity, EGC, GC, ECg followed next, and the activity of EC was lowest. These data suggest that the presence of the three adjacent hydroxyl groups (pyrogallol or galloyl group) in the molecule would be a key factor for enhancing the activity. Since reactive oxygen species play an important role in cell death induction, radical scavenging activity was evaluated using the DPPH (1,1-diphenyl-2-picrylhydrazyl) radical. The order of scavenging activity was ECg $\geq$ EGCg $\geq$ EGC $\geq$ GC $\geq$ EC. The compounds having a galloyl moiety showed more potent activity. The contribution of the pyrogallol moiety in the B-ring to the scavenging activity seemed to be less than that of the galloyl moiety.
\end{abstract}

Key words green tea; human stomach cancer; flavan-3-ol; antiproliferative activity; radical scavenging activity

Green tea [Camellia sinensis (L.) O. Kuntze, Theaceae] has a longstanding reputation in Asia for its health-promoting properties. ${ }^{2)}$ Epidemiological studies have suggested that the consumption of green tea provides protection against stomach cancer., ${ }^{3,4)}$ In a rural area of northern Kyushu, Japan, a decreased risk of stomach cancer was also noted among cases reporting a high consumption of green tea. ${ }^{5}$ Numerous in vitro and in vivo studies on green tea preparations have demonstrated the antimutagenic, anticarcinogenic, and antioxidant properties of the flavan-3-ols which form the major portion of soluble tea constituents. ${ }^{2)}$ However, although other ingredients such as caffeine and flavonol glycosides are also contained in green tea, there is no report in regard to antiproliferative activity-guided fractionation using human stomach cancer cells.

In the course of our continuing studies on the antiproliferative principles in plants, ${ }^{6-13)}$ we found that a hot water extract of green tea leaves inhibits the growth of human stomach cancer (MK-1) cells. This paper deals with the isolation of the active principles by activity-guided fractionation and the structure-activity relationship. Further, since reactive oxygen species play an important role in cell death induction, ${ }^{14)}$ radical scavenging activity ${ }^{15,16)}$ of the isolated antiproliferative compounds were also tested and compared to determine the correlation between the two activities.

\section{MATERIALS AND METHODS}

Materials The processed green tea leaves (Camellia sinensis, Theaceae) were supplied by Saga Tea Experimental Station, Ureshino, Saga Prefecture, Japan.

Extraction and Isolation The processed green tea leaves $(200 \mathrm{~g})$ were extracted with hot water. The detailed procedure for the fractionation of the extract and isolation of the constituens is shown in Chart 1.
Cells MK-1 cells were provided by Prof. M. Katano, Faculty of Medicine, Kyushu University.

Determination of Antiproliferative Activity Inhibition of cellular growth was estimated using the 3-(4,5-dimethylthiazol-2-yl)-2,5-diphenyltetrazolium bromide (MTT) assay described by Mosmann. ${ }^{17)}$

Measurement of DPPH Radical Scavenging Activity by ESR The DPPH (1,1-diphenyl-2-picrylhydrazyl) radical scavenging activity of the test sample was estimated by ESR, according to the method of Tateyama et al. ${ }^{18)}$

\section{RESULTS AND DISCUSSION}

Results of the activity-guided fractionation of green tea extract and the isolation of constituents are summarized in Chart 1. First, the green tea extract was divided into three fractions (Frs. 1-3) by Diaion HP-20 column chromatography. The latter two fractions (Frs. 2, 3) showed potent antiproliferarive activity, while Fr. 1, including sugars, amino acids, and so on, was negative.

Sephadex LH-20 column chromatography of Fr. 2, followed by reversed-phase silica gel chromatography (YMC gel-AQ), yielded compounds 2 and 4 . Fraction 3, which showed potent activity, was further fracionated into four subfractions (Frs. 3-1-3-4). As shown in Chart 1, Fr. 3-1 which contained caffeine exhibited no activity. Fraction 3-2 showed less potent activity, while Frs. 3-3 and 3-4 showed potent activity. Repeated column chromatography of Fr. 3-3 by YMC gel-AQ gave compounds 1 and 2. Similarly, Fr. 3-4 gave compounds $\mathbf{3}, \mathbf{5}$ and $\mathbf{6}$. The less active fraction (Fr. 3-2) was also subjected to YMC gel-AQ chromatography to afford compounds $7, \mathbf{8}$ and $\mathbf{9}$. Compounds $\mathbf{1}-\mathbf{8}$ were identified as epicatechin, ${ }^{19)}$ epigallocatechin, ${ }^{19)}$ epigallocatechin gallate, ${ }^{19}$ gallocatechin, ${ }^{19)}$ epicatechin gallate, ${ }^{19)}$ gallocatechin gallate, ${ }^{19)}$ kaempferol 3-O-glucosyl-( $(1 \rightarrow 3)$-rhamnosyl-( $(1 \rightarrow 6)$-galacto- 


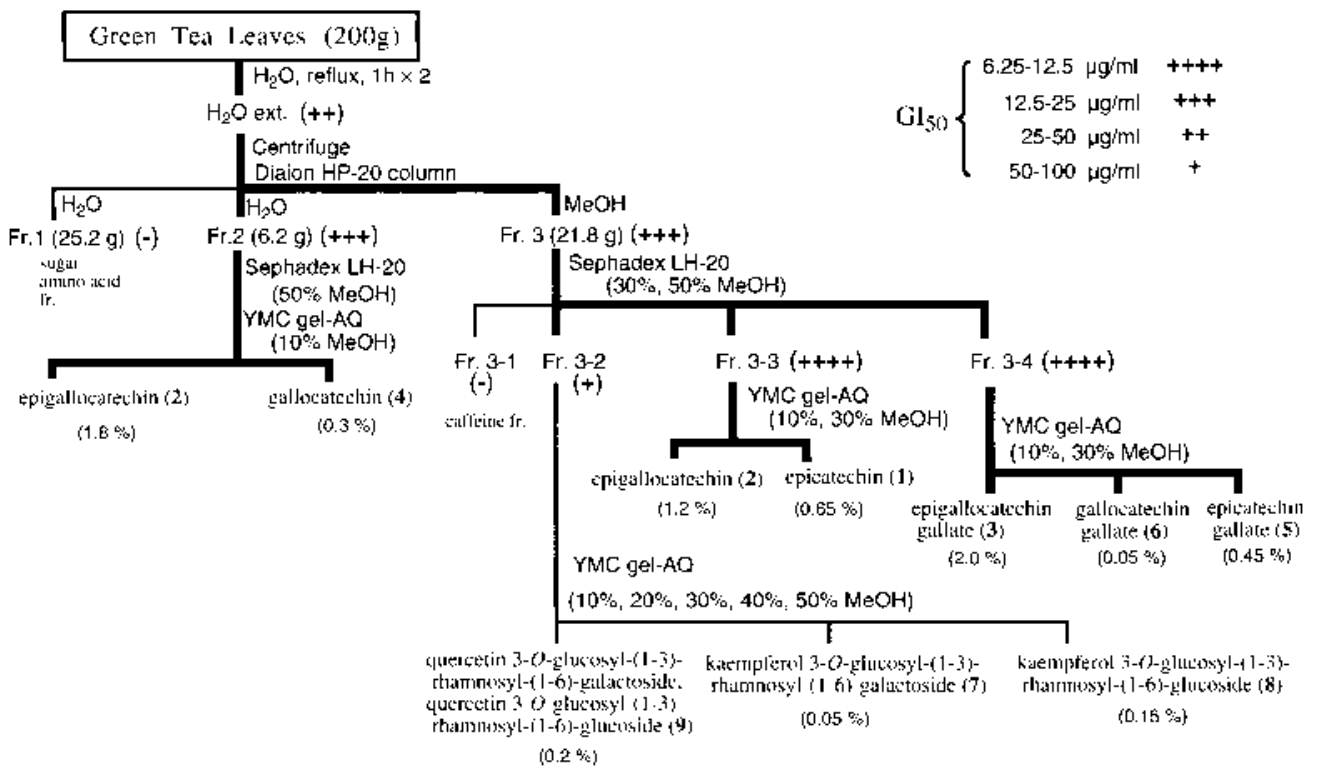

Chart 1. Activity-Guided Fractionation of Green Tea Extract and Isolation of Active Principles
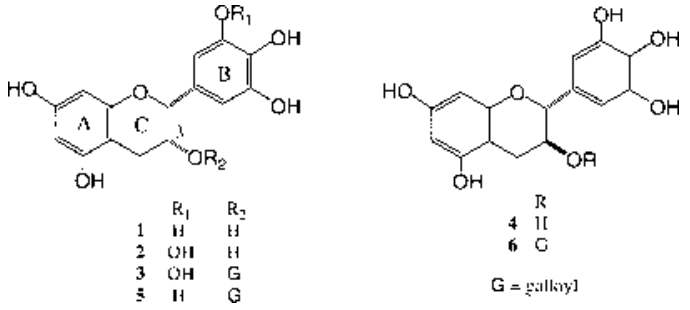

Fig. 1. Antiproliferative Flavan-3-ols in Green Tea

side $^{20)}$ and kaempferol 3-O-glucosyl-( $\left.1 \rightarrow 3\right)$-rhamnosyl- $(1 \rightarrow$ $6)$-glucoside, ${ }^{20}$ respectively, by comparison of their physical data with those reported. Compound 9 was identified as a mixture of quercetin 3-O-glucosyl- $(1 \rightarrow 3)$-rhamnosyl- $(1 \rightarrow 6)$ galactoside and quercetin 3-O-glucosyl-( $\rightarrow 3)$-rhamnosyl$(1 \rightarrow 6)$-glucoside. $\left.{ }^{20}\right)$

The antiproliferative activity of $\mathbf{1}-\mathbf{9}$ was determined by MTT assay, and their $\mathrm{GI}_{50}$ values are listed in Table 1 .

All flavan-3-ols (1-6) showed potent activity. Compounds 3 and 6 showed the highest activity of all, and 2, 4 and $\mathbf{5}$ showed moderate activity. Compound $\mathbf{1}$ showed the lowest activity. Flavonol glycosides (7-9) did not show any antiproliferative activity. Although there are some structural similarities (the substitution patterns of the hydroxy groups in A- and B-rings) between $\mathbf{1}$ and 9, compound 9 did not show any activity. Therefore, the saturated C-ring, like flavan-3-ols, might influence the antiproliferative activity against MK-1 cells.

In spite of a configurational difference at C-3, the $\mathrm{GI}_{50}$ value of $\mathbf{2}$ was the same as that of $\mathbf{4}$, and the $\mathrm{GI}_{50}$ values of $\mathbf{3}$ and 6 were equal, indicating that the configuration at C-3 would not affect the antiproliferative activity. The $\mathrm{GI}_{50}$ values of 2, 4 and 5 (gallate of 1) were about one-third that of $\mathbf{1}$. These data suggest that the presence of three adjacent hydroxyl groups (pyrogallol or galloyl group) in the molecule would be a key factor for enhancing the activity. Finally, the activity of $\mathbf{3}$, having a pyrogallol moiety in the B-ring and
Table 1. Antiproliferative Activity $\left(\mathrm{GI}_{50}, \mu \mathrm{M}\right)$ against Human Stomach Cancer (MK-1) Cells and DPPH Radical Scavenging Activity $\left(\mathrm{IC}_{50}, \mu \mathrm{M}\right)$

\begin{tabular}{crc}
\hline \hline Compounds & $\mathrm{GI}_{50}(\mu \mathrm{M})$ & $\mathrm{IC}_{50}(\mu \mathrm{M})$ \\
\hline $\mathbf{1}$ & 45 & 10.6 \\
$\mathbf{2}$ & 14 & 7.5 \\
$\mathbf{3}$ & 9 & 6.3 \\
$\mathbf{4}$ & 14 & 9.4 \\
$\mathbf{5}$ & 14 & 5.9 \\
$\mathbf{6}$ & 10 & N.T. \\
$\mathbf{7}$ & $>132$ & N.T. \\
$\mathbf{8}$ & $>132$ & N.T. \\
$\mathbf{9}$ & $>130$ & N.T. \\
\hline
\end{tabular}

N.T.: Not tested.

galloyl moiety at C-3, was five times higher than that of $\mathbf{1}$.

Inoue et al. demonstrated that three adjacent phenolic hydroxyl groups of gallic acid should be essential to cytotoxicity. ${ }^{21)}$ They also disclosed that the cell death induced by gallic acid was accompanied by internucleosomal DNA fragmentation characteristic of apoptosis. ${ }^{22)}$ Hibasami et al. also reported that the green tea extract and $\mathbf{3}$ showed both growth inhibition and the induction of programmed cell death (apoptosis) against human stomach cancer KATO III cells. ${ }^{23)}$ Since reactive oxygen species play an important role in cell death induction, ${ }^{14}$ the DPPH radical scavenging activity of some active flavan-3-ols ( $\mathbf{1 - 5}$ ) was measured by ESR (Table 1). Although $\mathbf{1}-\mathbf{5}$ showed DPPH radical scavenging activity, their potencies were different. Unexpectedly, the number of hydoxyl group was not directly proportional to the activity. The order of scavenging activity was $\mathbf{5} \geq \mathbf{3} \geq \mathbf{2} \geq \mathbf{4} \geq \mathbf{1}$. The compounds having a galloyl moiety showed more potent activity. The contribution of the pyrogallol moiety in B-ring to the scavenging activity seemed to be less than that of the galloyl moiety at C-3, although both moieties were a key factor in enhancing the antiproliferative activity.

In conclusion, the water extract of green tea showed antiproliferative activity against human stomach cancer (MK-1) 
cells. By activity-guided fractionation, six flavan-3-ols (16) were isolated as active principles. The structure-antipoliferative activity relationship was slightly correlated with that of radical scavenging activity.

Acknowledgements The authors express their gratitude to Mr. M. Muraoka and Mr. N. Tanaka of Saga Tea Experimental Station for supplying the processed green tea leaves. This work was supported by a Grant-in-Aid for Scientific Research (C) (No. 12672080) from the Ministry of Education, Culture, Sports, Science and Technology, Japan and by funds (No. 006006) from the General Research Insitute of Fukuoka University.

\section{REFERENCES AND NOTES}

1) Antiproliferative Constituents in the Plant 11. Part 10: Nagao T., Abe F., Kinjo J., Okabe H., Biol. Pharm. Bull., 25, 875-879 (2002).

2) Kim M., Masuda M., "Chemistry and Applications of Green Tea," ed. by Yamamoto T., Juneja L. R., Chu D. C., Kim M., CRC Press, Boca Raton, 1997, pp. 61-73.

3) Yu G. P., Hsieh C. C., Wang L. Y., Yu S. Z., Li X. L., Jin T. H., Cancer Causes Control, 6, 532-538 (1995).

4) Setiawan V. W., Zhang Z. F., Yu G. P., Lu Q. Y., Li Y. L., Lu M. L., Wang M. R., Guo C. H., Yu S. Z., Kurtz R. C., Hsieh C. C., Int. J. Cancer, 92, 600-604 (2001).

5) Kono S., Ikeda M., Tokudome S., Kuratsune M., Jpn. J. Cancer Res., 79, $1067-1074$ (1988).

6) Castro V. H., Ramirez E., Mora G. A., Iwase Y., Nagao T., Okabe H., Matsunaga H., Katano M., Mori M., Chem. Pharm. Bull., 45, 349358 (1997).

7) Nakano Y., Matsunaga H., Saita T., Mori M., Katano M., Okabe H.,
Biol. Pharm. Bull., 21, 257-261 (1998).

8) Ikeda R., Nagao T., Okabe H., Nakano Y., Matsunaga H., Katano M., Mori M., Chem. Pharm. Bull., 46, 871-874 (1998).

9) Ikeda R., Nagao T., Okabe H., Nakano Y., Matsunaga H., Katano M., Mori M., Chem. Pharm. Bull., 46, 875-878 (1998).

10) Furumi K., Fujioka T., Fujii H., Okabe H., Nakano Y., Matsunaga H., Katano M., Mori M., Mihashi K., Bioorg. Med. Chem. Lett., 8, 93-96 (1998).

11) Fujioka T., Furumi K., Fujii H., Okabe H., Mihashi K., Nakano Y., Matsunaga H., Katano M., Mori M., Chem. Pharm. Bull., 47, 96-100 (1999).

12) Nagao T., Abe F., Okabe H., Biol. Pharm. Bull., 24, 1338-1341 (2001).

13) Kinjo J., Nagao T., Tanaka T., Nonaka G., Okabe, H., Biol. Pharm. Bull., 24, 1443-1445 (2001).

14) Inoue M., Sakaguchi N., Isuzugawa K., Tani H., Ogihara Y., Biol. Pharm. Bull., 23, 1153-1157 (2000).

15) Okawa M., Kinjo J., Nohara T., Ono M., Biol. Pharm. Bull., 24, $1202-1205$ (2001).

16) Okawa M., Kinjo J., Yang C. R., Nonaka G., Nohara T., Natural Medicines, 55, 209-212 (2001).

17) Mosmann T., J. Immunol. Methods, 65, 55-63 (1983).

18) Tateyama C., Ohta M., Uchiyama T., Nippon Kagaku Kougaku Kaishi, 44, 640-646 (1997).

19) Nonaka G., Kawahara O., Nishioka I., Chem. Pharm. Bull., 31, 3906 3914 (1983).

20) Finger A., Engelhardt U. H., Wray V., Phytochemistry, 30, 20572060 (1991).

21) Inoue M., Suzuki R., Sakaguchi N., Li Z., Takeda T., Ogihara Y., Jiang B. Y., Chen Y., Biol. Pharm. Bull., 18, 1526-1530 (1995).

22) Sakaguchi N., Inoue M., Isuzugawa K., Ogihara Y., Hosaka K., Biol. Pharm. Bull., 22, 471—475 (1999).

23) Hibasami H., Komiya T., Achiwa Y., Ohnishi K., Kojima T., Nakanishi K., Akashi K., Hara Y., Oncology Reports, 5, 527-529 (1998). 